\title{
A Red Cy3-Based Biarsenical Fluorescent Probe Targeted to a Complementary Binding Peptide
}

Haishi Cao, Yijia Xiong, Ting Wang, Baowei Chen, Thomas C. Squier and M. Uljana Mayer*

Biological Sciences Division; Pacific Northwest National Laboratory; Richland, WA 99352

Uljana.Mayer@pnl.gov

Contents:

page

$\begin{array}{ll}\text { Figure S1.Binding Curve with Residuals } & \text { S2 }\end{array}$

$\begin{array}{ll}\text { Figure S2. Kinetics } & \text { S3 }\end{array}$

$\begin{array}{ll}\text { Synthesis } & \text { S4 }\end{array}$

$\begin{array}{ll}\text { Characterization } & \text { S5 }\end{array}$

$\begin{array}{ll}\text { References } & \text { S7 }\end{array}$

$\begin{array}{ll}\text { Manuscript with a larger number of references } & \text { S8 }\end{array}$ 


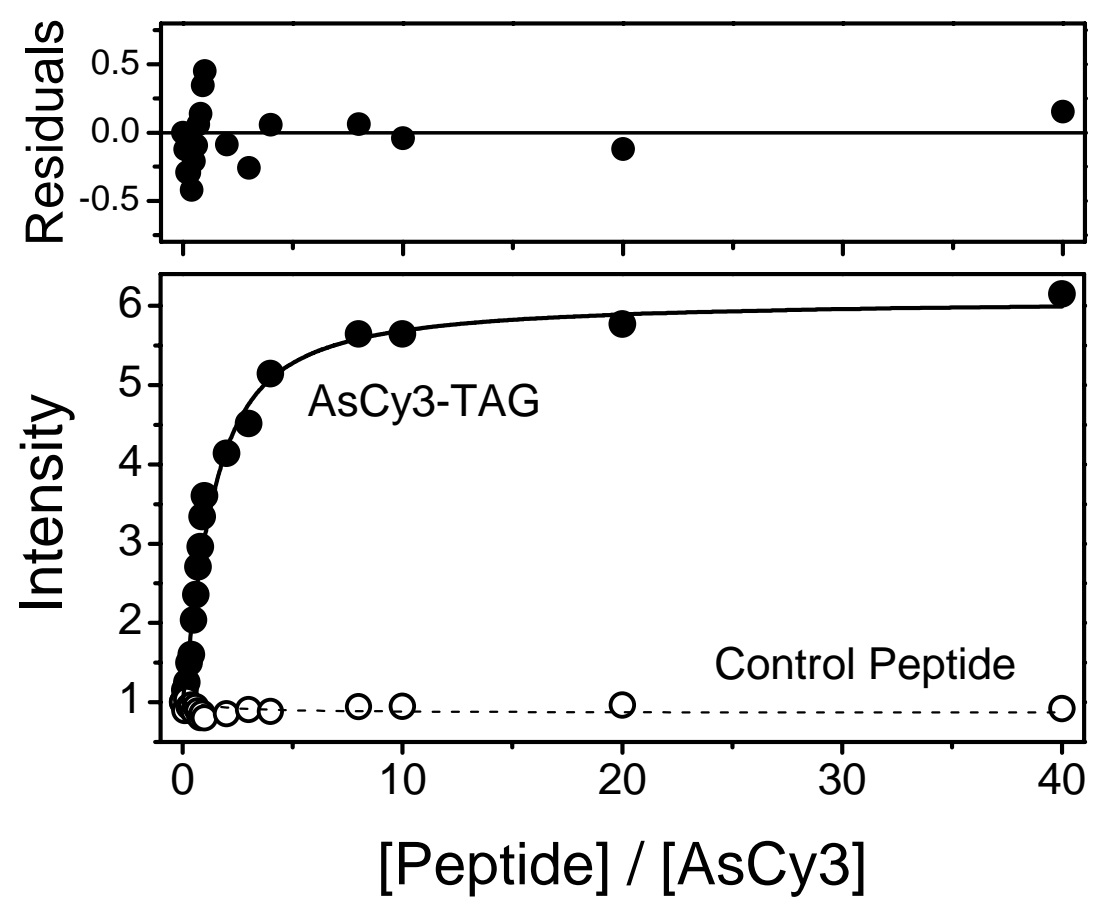

Figure S1: Binding Curve with Residuals. Fluorescence enhancement of AsCy3 $(1 \mu \mathrm{M})$ associated with addition of Cy3TAG on the CaM-binding sm-MLCK peptide (•)(Ala-Arg-Arg-Lys-Trp-Gln-LysThr-Gly-His-Ala-Val-Arg-Ala-Ile-Gly-Arg-Leu-Ser-Ser-Ala-Cys-Cys-Lys-Ala-Glu-Ala-Ala-Cys-CysGlu-Ala-Ala-Lys) or control sm-MLCK peptide (O) deficient in Cy3TAG (i.e., Ala-Arg-Arg-Lys-TrpGln-Lys-Thr-Gly-His-Ala-Val-Arg-Ala-Ile-Gly-Arg-Leu-Ser) (Lower Panel) and residuals from nonlinear least squares fit to Eq. 9 (see below), where $\mathrm{K}_{\mathrm{d}}=80 \pm 10 \mathrm{nM}$ (Upper Panel). 


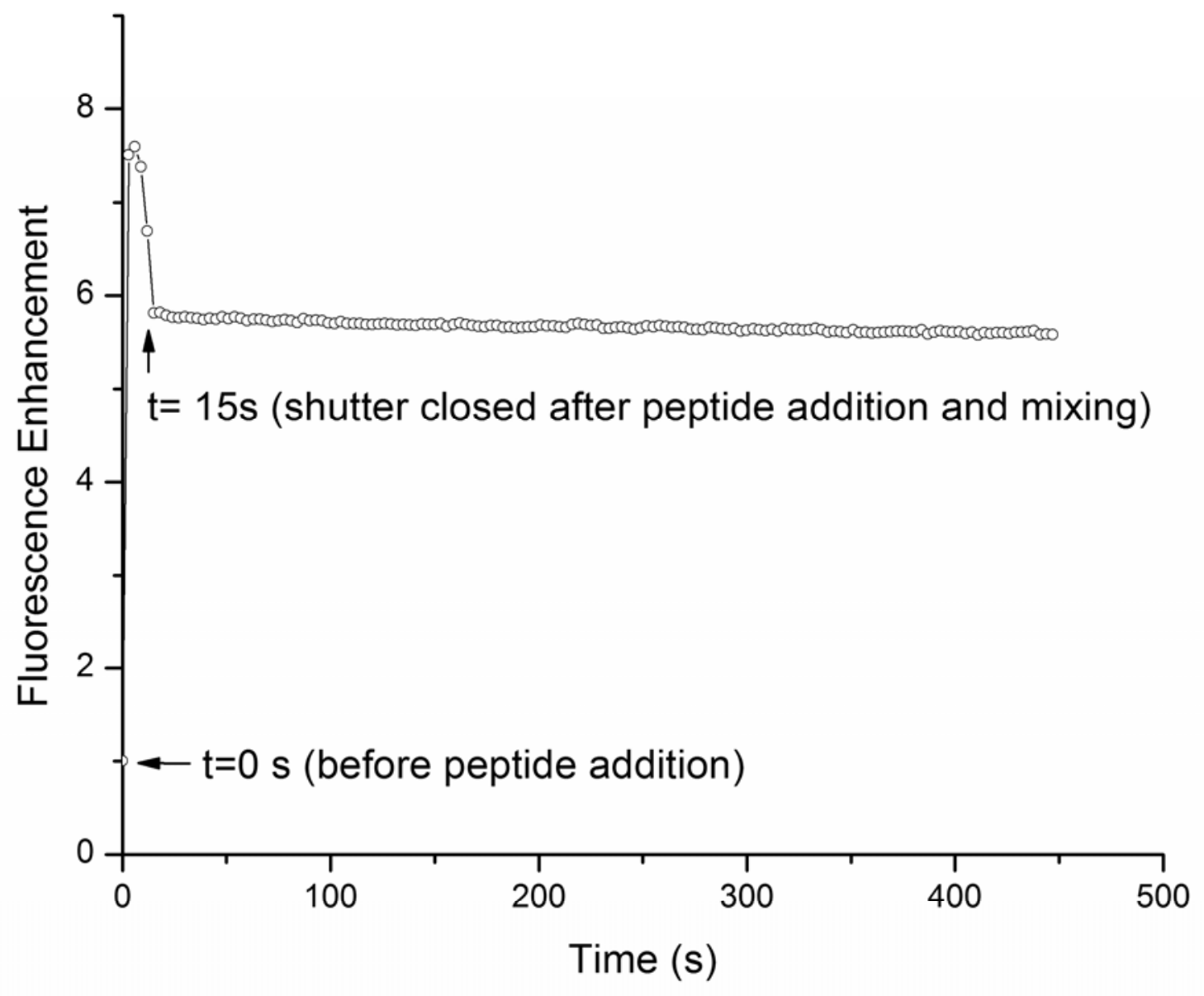

Figure S2. Kinetics. When reduced Cy3TAG peptide $(1 \mu \mathrm{M})$ is added to AsCy3 $(0.1 \mu \mathrm{M})$ in buffer A with $5 \mathrm{mM}$ TCEP, the reaction is complete before the first time point is taken 15 seconds after addition (reaction monitored by fluorescence enhancement at $576 \mathrm{~nm}$, excitation at $545 \mathrm{~nm}$ ). 


\section{Materials and Methods:}

General: All synthetic manipulations were performed under dry argon atmosphere using standard techniques. ${ }^{1} \mathrm{H}$ and ${ }^{13} \mathrm{C}$ NMR spectra were recorded using a Varian 500 spectrometer $\left(500 \mathrm{MHz}\right.$ for ${ }^{1} \mathrm{H}$ and $125 \mathrm{MHz}$ for ${ }^{13} \mathrm{C}$ ). Mass spectra were recorded using a Agilent 1100 series LC/MSD. Absorption spectra were recorded using a Nicolet Evolution $300 \mathrm{uv} / \mathrm{vis}$ spectrophotometer (Thermoelectron Corp). A FluoroMax-2 fluorometer (HORIBA Jobin Yvon Inc.) was used for all of fluorescence measurements. Reagents were obtained from Sigma-Aldrich, unless otherwise noted, and used without further purification. Peptides, i.e., sm-MLCK peptide-Cy3TAG (Ala-Arg-Arg-Lys-Trp-Gln-Lys-Thr-Gly-His-Ala-Val-Arg-Ala-Ile-Gly-Arg-Leu-Ser-Ser-Ala-Cys-CysLys-Ala-Glu-Ala-Ala-Cys-Cys-Glu-Ala-Ala-Lys) and control sm-MLCK peptide (Ala-Arg-Arg-LysTrp-Gln-Lys-Thr-Gly-His-Ala-Val-Arg-Ala-Ile-Gly-Arg-Leu-Ser) were obtained at $>90 \%$ purity from CPC Scientific (San Jose, CA). Calmodulin with four cysteines inserted at positions 6, 7, 10, and 11 in helix A (i.e., C4-CaM) was expressed and purified as previously described. ${ }^{1}$

\section{AsCy3 Synthesis:}

1- $\boldsymbol{\delta}$-Sulfobutyl-2,3,3-trimethyl-indolenine (1) A mixture of 2,3,3-trimethyl-indole (0.80g, $5.0 \mathrm{mmol})$ and 1,4-butane sultone $(2.25 \mathrm{~g}, 16 \mathrm{mmol})$ in $7 \mathrm{~mL}$ of 1,2-dichlorobenzene was refluxed at $120^{\circ} \mathrm{C}$ for 12 $\mathrm{hr}$ under an Argon atmosphere. After cooling, the reaction mixture was dropped into cold acetone (100 $\mathrm{mL})$ and the precipitate collected. $1-\delta$-Sulfobutyl-2,3,3-trimethyl-indolenine (1, pink powder) was washed with acetone $(20 \mathrm{~mL})$ three times, yield 69\%. ${ }^{1} \mathrm{H}$ NMR (DMSO): $1.54(\mathrm{~s}, 6 \mathrm{H}), 1.74(t, J=7.3 \mathrm{~Hz}$, $2 H), 1.96(\mathrm{~m}, 2 \mathrm{H}), 2.45(\mathrm{~m}, 2 \mathrm{H}), 2.84(\mathrm{~s}, 3 \mathrm{H}), 4.48(\mathrm{t}, \mathrm{J}=4.5 \mathrm{~Hz}, 2 \mathrm{H}), 7.62(\mathrm{~m}, 2 \mathrm{H}), 7.84(\mathrm{t}, \mathrm{J}=4.0 \mathrm{~Hz}$, $1 H), 8.04(d, J=6.5 H z, 1 H) .{ }^{13} \mathrm{C}$ NMR (DMSO): 14.53, 22.68, 22.84, 26.78, 48.01, 50.81, 54.82, 116.23, 124.16, 129.71, 130.17, 141.89, 142.64. ESI/MS: m/z calcd. for $[\mathrm{M}+\mathrm{H}]^{+} 296.1$, found 296.1

3-(3,3-dimethyl-1-(4-sulfobutyl)indolin-2-ylidene)prop-1-enyl)-3,3-dimethyl-1-(4-sulfobutyl)-3Hindolium (2) Compound 1 (100 mg, $0.34 \mathrm{mmol}, 1.0$ eq.) and triethyl orthoformate (101 $\mathrm{mg}, 0.68 \mathrm{mmol}$, 2.0 eq.) were heated together in a buffered acetic anhydride/ acetic acid mixture ( $1.5 \mathrm{~mL}$ acetic acid, $1.1 \mathrm{~mL}$ acetic anhydride and $0.065 \mathrm{~g}$ sodium acetate) at $120^{\circ} \mathrm{C}$ for $12 \mathrm{hrs}$. After the reaction, the solvent was removed and the residue was dissolved in MeOH. 3-(3,3-dimethyl-1-(4-sulfobutyl)indolin-2ylidene) prop-1-enyl)-3,3-dimethyl-1-(4-sulfobutyl)-3H-indolium (2) was purified by silica gel TLC (ethyl acetate : $\mathrm{MeOH}=6: 5 \mathrm{v} / \mathrm{v}$ ) with a 90\% yield. ${ }^{1} \mathrm{H}$ NMR (DMSO): $1.62(\mathrm{~s}, 12 \mathrm{H}), 1.72(\mathrm{~m}, 8 \mathrm{H}), 2.51$ (m, 4H), $4.10(m, 4 H), 6.54(d, J=13.5 H z, 2 H), 7.26(t, J=7.5 H z, 2 H), 7.39(t, J=7.5 H z, 2 H), 7.45(d$, $J=7.5 \mathrm{~Hz}, 2 \mathrm{H}), 7.59(d, J=7.5 \mathrm{~Hz} 2 \mathrm{H}), 8.31(t, J=14.0 \mathrm{~Hz} 1 \mathrm{H}) .{ }^{13} \mathrm{C}$ NMR (DMSO):22.4, 27.3, 28.2, 44.3, 48.9, 49.1, 51.8, 103.3, 112.2, 123.1, 125.9, 129.7, 141.5, 142.8, 150.7, 174.6. ESI/MS: m/z calcd. for $[\mathrm{M}+\mathrm{H}]^{+} 600.3$, found 600.8

3-(5-(1,3,2-dithiarsolan-2-yl)-3,3-dimethyl-1-(4-sulfobutyl)indolin-2-ylidene)prop-1-enyl)-5-(1,3,2dithiarsolan-2-yl)-3,3-dimethyl-1-(4-sulfobutyl)-3H-indolium (AsCy3) Cy3 (2) (189 mg, 0.30 mmol, 1.0 eq.) was added into trifluoroacetic acid $(4.0 \mathrm{~mL})$ containing mercuric oxide $(216 \mathrm{mg}, 0.60$ mmol, 2.0 eq.) at room temperature. After overnight stirring, the reaction mixture was evaporated. Pink precipitate (Cy3- bis-mercuric trifluoroacetate, $304 \mathrm{mg}$ ) (3) was collected by filtration with 75\% yield. After drying under high vacuum, Cy3- bis-mercuric trifluoroacetate (304 mg) was suspended in dry Nmethylpyrrolidinone (NMP, 3.5mL) with arsenic trichloride (300 $\mu \mathrm{L}, 6.2 \mathrm{mmol}, 27$ eq.), diisopropyl ethyl amine (DIEA, $220 \mu \mathrm{L}, 2.3 \mathrm{mmol}$, 10eq.) and catalytic palladium acetate $(20 \mathrm{mg})$. The reaction was stirred at room temperature for 8 hours. After reaction, $10 \mathrm{~mL} 0.25 \mathrm{M}$ phosphate buffer $\mathrm{pH} 7$ and 1,2ethanedithiol (10 mmol, 44 eq.) were added into reaction mixture. The solution was extracted with $\mathrm{CHCl}_{3}(3 \times 30 \mathrm{~mL})$, dried over $\mathrm{Na}_{2} \mathrm{SO}_{4}$, evaporated and purified by chromatography on silica gel $(\mathrm{MeOH}$ : toluene $=1: 2 \mathrm{v} / \mathrm{v})$ with an 81\% yield. ${ }^{1} \mathrm{H}$ NMR (DMSO): 1.70-1.82 (m, 20H), $2.45(\mathrm{~m}, 4 \mathrm{H}), 3.21(\mathrm{~m}, 8 \mathrm{H})$, $4.14(m, 4 H), 6.61(d, J=13.5 H z, 2 H), 7.53(d, J=7.5 H z, 2 H), 7.72(d, J=8.0 H z, 2 H), 7.87(s, 2 H), 8.33(t$, 
$J=14.0 \mathrm{~Hz}, 1 \mathrm{H}$ ). ${ }^{13} \mathrm{C}$ NMR (DMSO):22.4, 27.2, 28.1, 42.3, 49.2, 49.3, 51.5, 95.1, 104.1, 112.0, 123.1, 125.0, 131.8, 141.2, 143.4, 150.5, 174.4. ESI/MS: m/z calcd. for $[\mathrm{M}+\mathrm{H}]^{+} 933.0185$, found 933.0186

\section{Characterization:}

Absorption and emission spectra of AsCy3. Spectra were measured in 50 mM HEPES (pH 7.5), 10\% DMSO (v/v) and $140 \mathrm{mM} \mathrm{KCl} \mathrm{(buffer} \mathrm{A)} \mathrm{in} \mathrm{the} \mathrm{presence} \mathrm{of} 1 \mathrm{mM}$ TCEP, $100 \mu \mathrm{M}$ EDT and $1 \mathrm{mM}$ BME. Absorbance spectra of AsCy3 were insensitive to peptide binding $\left(\lambda_{\max }=560 \mathrm{~nm}\right)$, while fluorescence emission maxima were red shifted from $\lambda_{\mathrm{em}}=568 \mathrm{~nm}$ for AsCy3 alone to $576 \mathrm{~nm}$ upon binding the Cy3TAG sequence. In all cases fluorescence excitation was at $545 \mathrm{~nm}$.

Peptide-Tag Labeling. Cy3TAG peptides (0 to $4 \mu \mathrm{M})$ were incubated in buffer A with $1 \mathrm{mM}$ TCEP, $100 \mu \mathrm{M}$ EDT and $1 \mathrm{mM} \mathrm{BME}$ at room temperature for 1 hour to reduce any disulfide bonds prior to incubation at $4{ }^{\circ} \mathrm{C}$ with $\mathrm{AsCy} 3(0.1 \mu \mathrm{M})$. Fluorescence emission spectra of AsCy3 bound to the Cy3TAG sequence were measured using a Fluoro Max-2 fluorometer (SPEX, Edison, NJ), using excitation at $545 \mathrm{~nm}$ and emission at $576 \mathrm{~nm}$. In all cases, the sample temperature was $25^{\circ} \mathrm{C}$. All spectra were collected after $2 \mathrm{hr}$ incubation at room temperature.

Binding Measurements. For equilibrium binding measurements, the extent of labeling was assessed after 2 hours, and the concentration of the Cy3TAG peptide that is in association with AsCy3, i.e., $[\mathrm{FP}]_{\text {bound, }}$ can be calculated such that,

$$
[F P]=\frac{\Delta F}{\Delta F_{\max }} \times[F]_{\text {total }}=\left[\frac{\left|\left(F-F_{0}\right)\right|}{\left|\left(F_{\text {max }}-F_{0}\right)\right|}\right] \times[F]_{\text {total }}
$$

where $\mathrm{F}_{0}$ is the initial fluorescence, $\mathrm{F}_{\max }$ is the fluorescence observed in the presence of saturating concentrations of peptide, and $\mathrm{F}$ is the observed fluorescence at a particular peptide concentration. $[F]_{\text {total }}$ is the concentration of $\mathrm{AsCy} 3$ in solution. Determination of the binding affinities assumes a ligand exchange mechanism whereby the binding of the vicinal cysteines within the target peptide to the two arsenics on $\mathrm{AsCy} 3$ involves the displacement of the bound EDT, as described by the following equilibrium.

$$
\text { AsCy3:EDT } 2+\text { Cy3-TAG } \rightarrow \text { AsCy3-Cy3-TAG Peptide complex }+2 \text { EDT }
$$

The dissociation constant, $\mathrm{K}_{\mathrm{d}}$ can be described as:

$$
K_{d}=\frac{[F][P]}{[F P][E D T]^{2}}
$$

where $[\mathrm{F}]$ and $[\mathrm{P}]$ represent the concentration of unbound AsCy3 and Cy3-TAG peptide, respectively. [EDT] represents the concentration of ethanedithiol, which must be in large excess of the AsCy3 reagent or peptide concentrations in order to calculate an apparent dissociation constant, $\mathrm{K}_{\mathrm{app}}$, as given by:

$$
K_{a p p}=K_{d}[E D T]^{2}=[F][P] /[F P]
$$

When the reaction is at equilibrium, then:

$$
\begin{aligned}
& {[F]_{\text {total }}=[F]+[F P]} \\
& {[P]_{\text {total }}=[P]+[F P]}
\end{aligned}
$$


where $[P]_{\text {total }}$ is the concentration of added peptide. Rearranging, the concentration of the dye-peptide complex $[\mathrm{FP}]$ can be solved, where:

$$
\begin{gathered}
{[F P]^{2}-\left([F]_{\text {total }}+[P]_{\text {total }}+K_{\text {app }}\right)[F P]+[F]_{\text {total }}[P]_{\text {total }}=0} \\
{[F P]=\left\{\left([F]_{\text {total }}+[P]_{\text {total }}+K_{\text {app }}\right)-\left[\left([F]_{\text {total }}+[P]_{\text {total }}+K_{\text {app }}\right)^{2}-4[F]_{\text {total }}[P]_{\text {total }}\right]^{1 / 2}\right\} / 2}
\end{gathered}
$$

Substitution of [FP] (se Eq. 1) yields:

$$
\Delta F=\Delta F_{\max }\left\{\left([F]_{\text {total }}+[P]_{\text {total }}+K_{\text {app }}\right)-\left[\left([F]_{\text {total }}+[P]_{\text {total }}+K_{\text {app }}\right)^{2}-4[F]_{\text {total }}[P]_{\text {total }}\right]^{1 / 2}\right\} / 2[F]_{\text {total }}
$$

FRET between FlAsH-derivatized CaM and AsCy3-derivatized CaM binding sequence smMLCK peptide: C4-CaM and Cy3TAG-sm-MLCK peptide were respectively labeled with FlAsH and AsCy3 with excess peptide and protein to ensure a known labeling yield of 36\%. FlAsH-labeled CaM $(1 \mu \mathrm{M})$ was titrated with AsCy3-labeled sm-MLCK peptide, where the peptide concentration was varied from 0 to $1 \mu \mathrm{M}$, in $0.2 \mu \mathrm{M}$ steps. Spectra were collected using $400 \mathrm{~nm}$ as excitation wavelength after $2 \mathrm{~h}$ incubation at room temperature in buffer $\mathrm{A}(\mathrm{pH} 7.5)$ with $1 \mathrm{mM} \mathrm{TCEP}$ and $1 \mathrm{mM} \mathrm{CaCl}_{2}$. The distance between the probes should be about 27 Angstrom based on the NMR structure, thus the observed energy transfer efficiency of $35 \%$ is a result of complete energy transfer for all peptides labeled with FRET acceptor AsCy3. This matches well with an expected transfer efficiency of $99 \%$ based on the calculated $\mathrm{R}_{0}$ of $65 \AA$.

Calculation of $\mathbf{R}_{\mathbf{0}}: \mathrm{R}_{0}$ was calculated using a home-written script (see screenshot, Figure S3) and the equation:

$$
R_{0}=0.211\left(\kappa^{2} n^{-4} \Phi_{d} J\right)^{1 / 6}
$$

where $\kappa^{2}$ is the orientation factor which is assumed to be $2 / 3 ; n$ is the refraction index which is assumed to be 1.4 for biomolecules in aqueous solution; $\Phi_{\mathrm{d}}$ is the quantum yield of the donor in the absence of acceptor and $J$ is the overlap integral:

$$
J=\int F(\lambda) \varepsilon(\lambda) \lambda^{4} d \lambda
$$

where $F(\lambda)$ is the fluorescence spectrum of donor with the total intensity normalized to unity and $\varepsilon(\lambda)$ is the extinction coefficient of the acceptor ${ }^{4}$. The units for the wavelength, the extinction coefficient and the Förster distance are nanometers, $\mathrm{M}^{-1} \mathrm{~cm}^{-1}$ and angstroms, respectively.

For FlAsH the published fluorescence quantum yield of FlAsH $\left(\Phi_{d}=\mathrm{Q}=0.59\right)^{3}$ and spectrum published on the Invitrogen web site (http://probes.invitrogen.com/servlets/spectra?fileid=TCFLASH ) were used. The Cy3TAG-bound AsCy3 extinction coefficient $\left(180000 \mathrm{~cm}^{-1} \mathrm{M}^{-1}\right)$ and absorbance spectrum were measured for this paper. The spectral overlap integral $J$ was determined to be $J=8.74 \times 10^{15} \mathrm{M}^{-1} \mathrm{~cm}^{-1}$ $(\mathrm{nm})^{4}$ or $8.74 \times 10^{-19} \mathrm{M}^{-1} \mathrm{~m}^{3}$. 


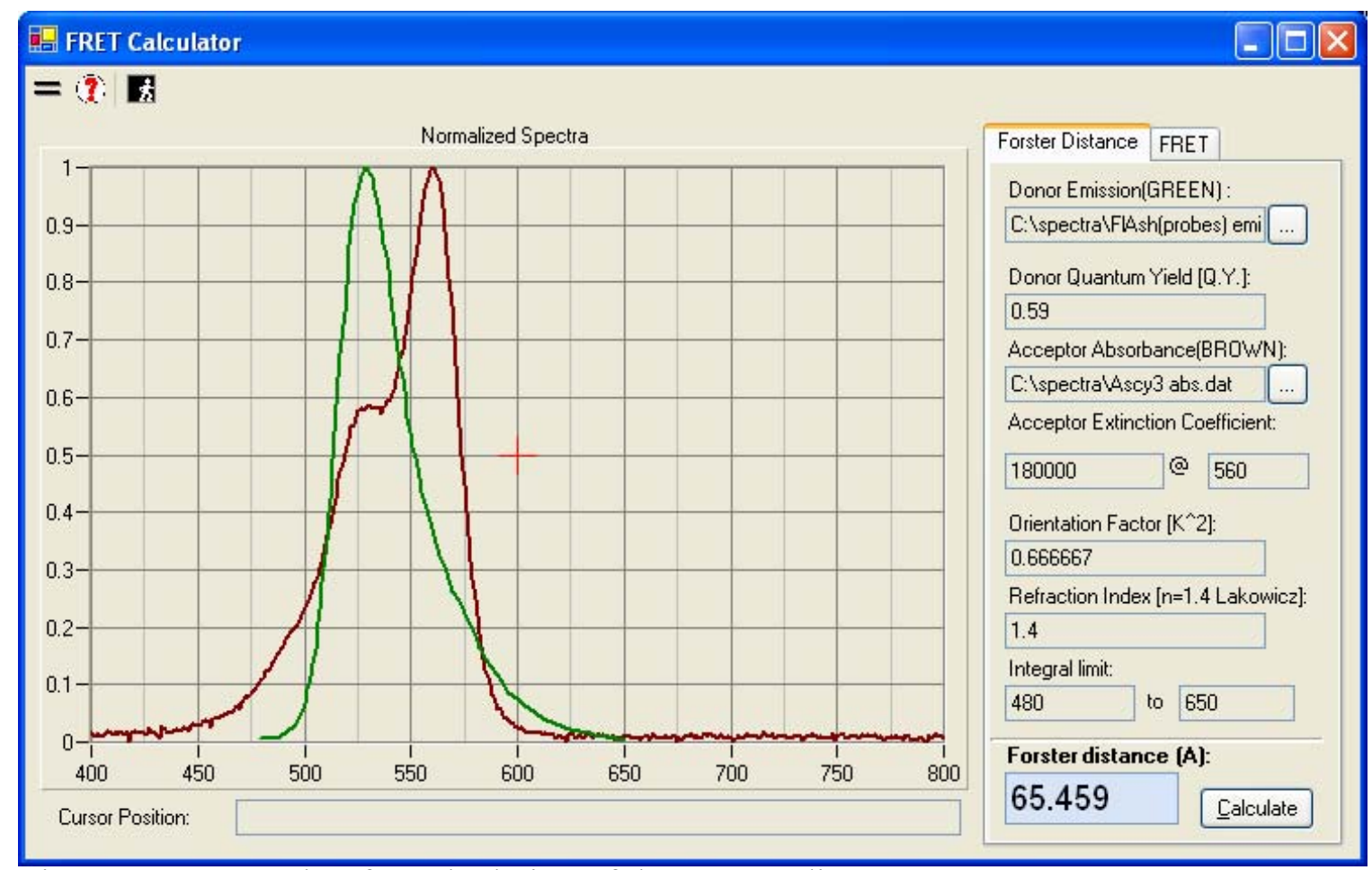

Figure S3. Screenshot for calculation of the Förster distance.

Selective Labeling of C4-CaM and the Cy3-TAG sm-MLCK peptide with FIAsH and AsCy3: A mixture of C4-CaM $(1.0 \mu \mathrm{M})$ and Cy3TAG-sm-MLCK peptide $(1.0 \mu \mathrm{M})$ were first incubated with AsCy3 $(1.0 \mu \mathrm{M})$ for one hour and then FlAsH $(1.0 \mu \mathrm{M})$ was added and incubated for another 1 hour in buffer A with $1 \mathrm{mM}$ TCEP. Sodium dodecylsulfate-polyacrylamide gel electrophoresis (SDS-PAGE) of labeled samples was performed using a 4-12\% Bis-Tris gels (Invitrogen, Carlsbad, CA). The FlAsHand AsCy3-labeled complexes were visualized on the unstained gel with a Kodak Imaging Station 2000MM (Kodak, Rochester, NY), containing appropriate filters for FlAsH detection (Kodak WA filters, Ex: 465 nm; Em: $535 \mathrm{~nm}$ ) and AsCy3 detection (Ex: $535 \mathrm{~nm}$; Em: $600 \mathrm{~nm}$ ).

\section{References:}

1. Chen, B.; Mayer, M. U.; Markillie, L. M.; Stenoien, D. L.; Squier, T. C., Biochemistry 2005, 44, (3), 905-914.

2. $\quad$ Panchal, R. G.; Ruthel, G.; Kenny, T. A.; Kallstrom, G. H.; Lane, D.; Badie, S. S.; Li, L. M.; Bavari, S.; Aman, M. J., Proc. Natl. Acad. Sci. U.S.A. 2003, 100, (26), 15936-15941.

3. Martin, B. R., B. N. G. Giepmans, S. R. Adams, and R. Y. Tsien. Mammalian cell-based optimization of the biarsenical-binding tetracysteine motif for improved fluorescence and affinity. Nat. Biotech. 2005, 23,1308-1314.

$4 \quad$ Lakowicz, J. R. 1999. Principles of Fluorescence Spectroscopy, Second Edition. Kluwer Academic/Plenum Publishers, New York 


\title{
A Red Cy3-Based Biarsenical Fluorescent Probe Targeted to a Complementary Binding Peptide
}

\author{
Haishi Cao, Yijia Xiong, Ting Wang, Baowei Chen, Thomas C. Squier, and M. Uljana Mayer* \\ Cell Biology and Biochemistry Group; Pacific Northwest National Laboratory; Richland, WA,USA \\ RECEIVED DATE (automatically inserted by publisher); Uljana.Mayer@pnl.gov
}

Small-molecule biarsenical multiuse affinity probes (MAPs) FlAsH and $\mathrm{ReAsH},{ }^{1-3}$ in conjunction with complementary protein tags, are important new tools for analyzing cellular function through live-cell imaging, ${ }^{4-7}$ targeted protein inactivation, ${ }^{8-10}$ and the measurement of protein dynamics and binding. ${ }^{11-13}$ In addition, MAPs serve as affinity reagents for isolating intact protein complexes for complementary structural measurements. ${ }^{14,15}$ These first-generation MAPs bind to a tetracoordinate arsenic group- (TAG) binding motif (i.e., CCXXCC or FlAsHTAG) genetically engineered onto a protein of interest. They are superior to other targeted labeling strategies (such as the Halo-tag, the SNAP tag, and fluorescent proteins) in that the small peptide tag does not disrupt protein-protein interactions nor perturb the correct trafficking of tagged proteins. ${ }^{16,17}$ The conserved interatomic distance $(\sim 6 \AA)$ between the two arsenic moieties in FlAsH, ReAsH and improved MAPs ${ }^{18,19}$ complicates the selective labeling of multiple proteins with different reporters. To overcome these limitations, we have synthesized a new biarsenical MAP (i.e., AsCy3) based on $\mathrm{Cy} 3$, a member of the cyanine dye family, whose well-recognized brightness and photostability facilitates their utility in singlemolecule measurements. The large interatomic distance between the two arsenics in AsCy3 $(\sim 14.5 \AA)$ coupled with the identification of a complementary high-affinity binding sequence CCKAEAACC (Cy3TAG) permits the simultaneous application of both AsCy3 and FlAsH to selectively label their respective binding TAGs in different proteins. In addition, the fluorescence of FlAsH overlaps with the absorption of $\mathrm{AsCy} 3$, which can act as an acceptor of fluorescence resonance energy transfer (FRET) to allow ratiometric measurements of protein association.

Scheme 1. Synthesis of AsCy3
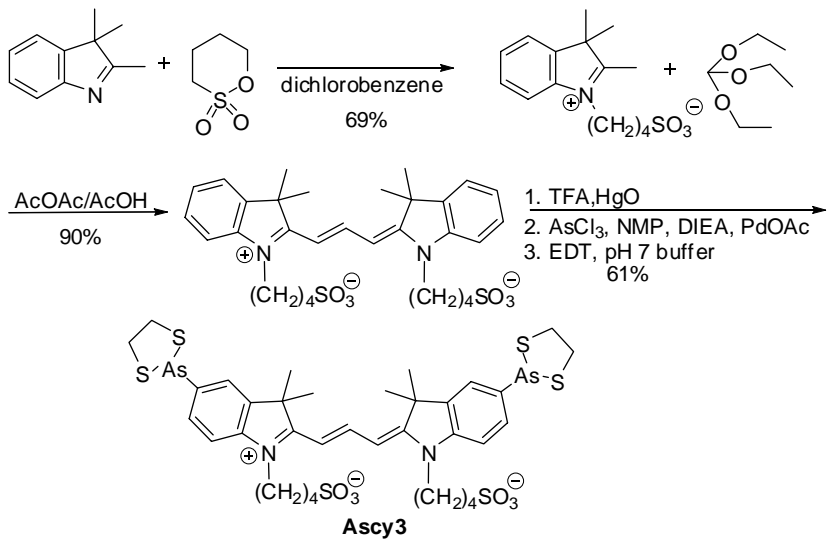

Synthesis of AsCy3 involved four steps (Scheme 1). Briefly, sulfonated $\mathrm{Cy} 3^{20,21}$ was prepared according to the procedure of $\mathrm{Li}$ et al., ${ }^{22}$ followed by mercuration and transmetallation to arsenic, which was liganded to ethanedithiol (EDT) for enhanced stability. ${ }^{3,19}$ The overall yield of $\mathrm{AsCy} 3$ was $38 \%$. Using 2DNMR to determine the structure of $\mathrm{AsCy} 3$ shows that the mercuration of the cyanine scaffold is specific with metal insertion para to the nitrogen group of the indoline ring system. Alternative synthetic routes, such as attaching the arsenic to the cyanine subunits prior to creating the linker region or synthesis of the linker region with a base, ${ }^{23}$ resulted in substantially lower yields.

The inter-arsenic distance in $\mathrm{AsCy} 3(14.5 \AA)$ was used in the design of a Cy3TAG binding sequence. Based on in silico distance measurements on NMR structures of alpha helices ${ }^{24,25}$ and hairpin-connected beta sheets, five different peptides were designed, and high-affinity binding was demonstrated for the Cy3TAG sequence CCKAEAACC (Figure 1, right panel). This sequence places two cysteine pairs two helical turns (i.e., $\sim 14 \AA$ ) apart, while the optimal FlAsH-binding motif was based on one helical turn and is improved by the even closer spacing provided by the proline-glycine turn. ${ }^{3,26}$ Binding is rapid and occurs in $<15$ seconds (see Supp. Figure S1) In comparison, FlAsH and ReAsH binding under similar conditions occurs in a time scale of several minutes. $^{27}$

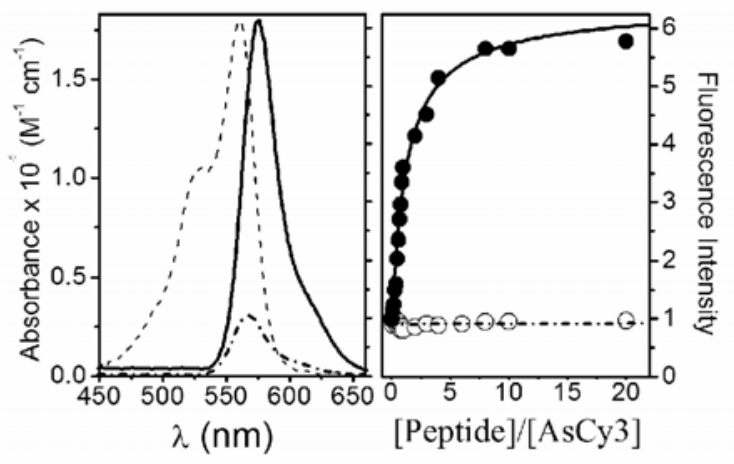

Figure 1. Left Panel: Identical absorbance spectra (----) and fluorescence emission spectra of AsCy3:EDT 2 (--.--) or the AsCy3-labeled Cy3TAG tag on the CaM-binding peptide M13 (-). Right Panel: Fluorescence enhancement of AsCy3 $(1 \mu \mathrm{M})$ associated with addition of Cy3TAG on sm-MLCK $(\bullet)$ or control sm-MCLK peptide (०) deficient in Cy3TAG.

The direct equimolar association between $\mathrm{AsCy} 3$ and the Cy3TAG can be fit assuming a simple Langmuir binding curve (Figure 1, Supp. Figure S2). AsCy3 binds to the Cy3TAG with high affinity (apparent $\mathrm{K}_{\mathrm{d}}=80 \pm 10 \mathrm{nM}$ ) in the presence of 100 $\mu \mathrm{M}$ EDT, which is commonly used to reduce nonspecific binding when labeling tagged proteins in cells. ${ }^{26}$ The observed binding affinity of $\mathrm{AsCy} 3$ to the $\mathrm{Cy} 3 \mathrm{TAG}$ is comparable to that for the 
association between FlAsH and FlAsHTAG in the presence of similar amounts of EDT, ${ }^{27}$ whose reported dissociation constant in the absence of added EDT is $\sim 10 \mathrm{pM}^{3,26}$

AsCy 3 has absorbance and fluorescence emission maxima at 560 and $568 \mathrm{~nm}$, respectively. The absorbance spectrum is insensitive to AsCy3 binding to the Cy3TAG and the release of EDT, while the fluorescence spectrum is red-shifted $\left(\lambda_{\max }=576\right.$ $\mathrm{nm}$ ) with a concomitant 6-fold increase in the fluorescence quantum yield $(\mathrm{Q}=0.28)$ (Figure 1 , left panel). The peptidebound $\mathrm{AsCy} 3$ conjugate has enhanced photostability in comparison to the corresponding peptide conjugates involving FlAsH and ReAsH, retaining optimal spectral intensity for extended periods of time; in comparison to FlAsH and $\mathrm{ReAsH}$ bleaching requires 3 - and $>30$-fold more light intensity, respectively. ${ }^{27}$ The fluorescence of $\mathrm{AsCy} 3$ is $\mathrm{pH}$-independent between 4 and 9 (data not shown), permitting accurate ratiometric measurements in applications involving FRET between FlAsH and $\mathrm{AsCy} 3$ at neutral $\mathrm{pH}$. Further, the large extinction coefficient (ع) of $180,000 \mathrm{M}^{-1} \mathrm{~cm}^{-1}$ yields a brightness $\left(\varepsilon \times \mathrm{Q}=5.0 \times 10^{4} \mathrm{M}^{-1}\right.$ $\left.\mathrm{cm}^{-1}\right)$ that is similar to that of FlAsH $\left(4-6 \times 10^{4} \mathrm{M}^{-1} \mathrm{~cm}^{-1}\right),{ }^{3,26}$ and considerably higher than the red probe ReAsH $\left(1-3 \times 10^{4} \mathrm{M}^{-1} \mathrm{~cm}^{-}\right.$ $\left.{ }^{1}\right) .{ }^{3,26}$ These properties suggest that $\mathrm{AsCy} 3$ will enjoy great utility in imaging applications.

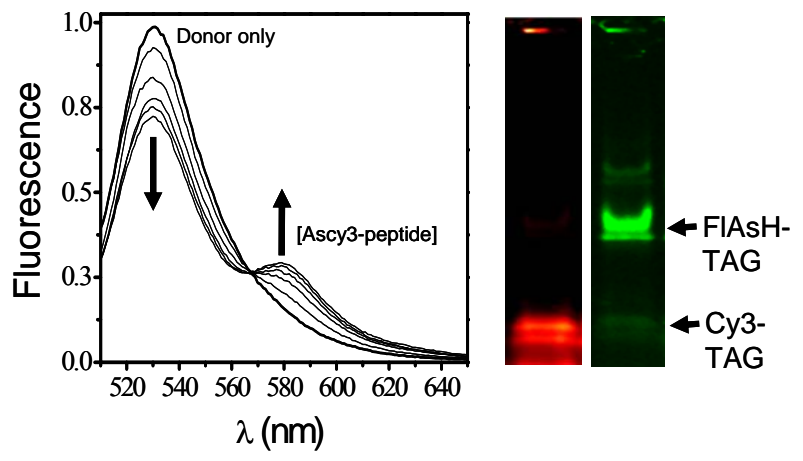

Figure 2. Left Panel: Fluorescence emission spectra of FlAsH-labeled CaM $(1 \mu \mathrm{M})$ titrated with AsCy3-labeled smMLCK peptide from 0 to 1.0 $\mu \mathrm{M}$ in $0.2 \mu \mathrm{M}$ increments. Right Panel: Labeling specificity of the FlAsHTAG in CaM and Cy3TAG in smMLCK reacted first with AsCy3, then FlAsH $($ all $1 \mu \mathrm{M})$. Same SDS-PAGE lane was imaged to detect $\mathrm{AsCy} 3$ (red) and FlAsH (green).

The identification of a new small-molecule biarsenical probe with a TAG orthogonal to that of FlAsH has considerable significance for the simultaneous labeling of multiple tagged proteins for biophysical measurements of protein complex formation and live-cell imaging. The utility of $\mathrm{AsCy} 3$ was demonstrated with the same model system used previously to show the selectively of FlAsH for live-cell imaging; that is, the calcium regulatory protein calmodulin $(\mathrm{CaM})$ with an engineered FlAsHTAG binding sequence in helix A. ${ }^{1}$ Binding specificity was assessed using an Cy3TAG on the CaM-binding sequence derived from smooth muscle myosin light chain kinase (i.e., smMLCK peptide), whose high-affinity binding complex $\left(\mathrm{K}_{\mathrm{d}}=1 \mathrm{nM}\right)$ has been determined. ${ }^{28}$ Following the formation of the complex between CaM and smMLCK peptide $(1 \mu \mathrm{M})$, AsCy3 $(1 \mu \mathrm{M})$ and FlAsH $(1 \mu \mathrm{M})$ were added sequentially prior to analysis by SDSPAGE (Figure 2, right panel). The extent of labeling was imaged using appropriate filters, demonstrating considerable selectivity in the labeling of the FlAsHTAG in CaM by FlAsH (green) and the Cy3TAG on the smMLCK peptide by AsCy (red). A densitometric analysis of the labeling specificity indicates a $>90 \%$ selectivity, indicating that $\mathrm{FlAsH}$ and $\mathrm{AsCy} 3$ can be used in the simultaneous labeling of different proteins for multicolor measurements. Further, binding can be directly measured by ratiometric methods suitable for cellular assays using $\mathrm{AsCy} 3$ as a FRET acceptor for FlAsH (Figure 2, left panel), where the Förster distance between this energy transfer pair is about $65 \AA$ (see Supp. Information).

Based on our experience with the cellular imaging of biarsenicals $^{7}$ and the common usage of cyanine dyes to this purpose ${ }^{29}$ we believe that the new AsCy3 platform will perform as well as the first generation of biarsenicals in in vivo imaging and extend their utility to two-color measurements of protein complexes whose function is disrupted by large tags.

In conclusion, we have synthesized a new biarsenical fluorescent probe, $\mathrm{AsCy} 3$, that in conjunction with a high-affinity binding motif (i.e., Cy3TAG) (CCKAEAACC) permits specific labeling of the Cy3TAG in the presence of the previously identified FlAsHTAG (CCXXCC). Further, AsCy3 provides a FRET partner to the biarsenical dye FlAsH, permitting measurements of protein-protein interactions. AsCy3 has superior photostability and a minimal environmental sensitivity compared to the existing biarsenical probes FlAsH and ReAsH. Thus, the discovery of the new biarsenical probe $\mathrm{AsCy} 3$ provides an important next step in developing a whole toolkit of colored probes directed to different small binding motifs.

Acknowledgments. We thank Ping Yan for synthesizing the FlAsH-EDT 2 . This research was supported by the Genomics: GTL program (Grant 45701) of the U.S. Department of Energy Office of Biological and Environmental Research. Pacific Northwest National Laboratory (PNNL) is operated for the DOE by Battelle Memorial Institute under Contract DE-AC05-76RL0 1830. A portion of the research was performed in the Environmental Molecular Sciences Laboratory, a national scientific user facility sponsored by DOE-BER and located at PNNL.

Supporting Information Available: Experimental procedures for the synthesis of AsCy3. Materials and methods for FRET and labeling experiments. Expanded figures for binding and kinetics. This material is available free of charge via the Internet at http://pubs.acs.org.

REFERENCES

1. Griffin, B. A.; Adams, S. R.; Tsien, R. Y., Science 1998, 281, (5374), 269-272.

2. $\quad$ Griffin, B. A.; Adams, S. R.; Jones, J.; Tsien, R. Y., Method Enzymol. 2000, 327, 565-578

3. Adams, S. R.; Campbell, R. E.; Gross, L. A.; Martin, B. R.; Walkup, G. K.; Yao, Y.; Llopis, J.; Tsien, R. Y., J. Am. Chem. Soc. 2002, 124, (21), 6063-6076

4. Panchal, R. G.; Ruthel, G.; Kenny, T. A.; Kallstrom, G. H.; Lane, D. Badie, S. S.; Li, L. M.; Bavari, S.; Aman, M. J., Proc. Natl. Acad. Sci. U.S.A. 2003, 100, (26), 15936-15941

5. Langhorst, M. F.; Genisyuerek, S.; Stuermer, C. A. O., Histochem. Cell. Biol. 2006, 743-747.

6. Gaietta, G.; Deerinck, T. J.; Adams, S. R.; Bouwer, J.; Tour, O.; Laird, D W.; Sosinsky, G. E.; Tsien, R. Y.; Ellisman, M. H., Science 2002, 296, (5567), 503-507.

7. Stenoien, D. L.; Knyushko, T. V.; Londono, M. P.; Opresko, L. K.; Mayer, M. U.; Brady, S. T.; Squier, T. C.; Bigelow, D. J., Am. J. Physiol. Cell. Physiol. 2007, published ASAP doi:10.1152/ajpcell.00523.2006

8. Yan, P.; Xiong, Y.; Chen, B.; Negash, S.; Squier, T. C.; Mayer, M. U., Biochemistry 2006, 45, (15), 4736-4748.

9. Tour, O.; Meijer, R. M.; Zacharias, D. A.; Adams, S. R.; Tsien, R. Y., Nat. Biotechnol. 2003, 21, (12), 1505-1508.

10. Marek, K. W.; Davis, G. W., Neuron 2002, 36, (5), 805-813.

11. Robia, S. L.; Flohr, N. C.; Thomas, D. D., Biochemistry 2005, 44, (11), $4302-4311$

12. Chen, B.; Mayer, M. U.; Squier, T. C., Biochemistry 2005, 44, (12), $4737-4747$

13. Chen, B.; Mayer, M. U.; Markillie, L. M.; Stenoien, D. L.; Squier, T. C., Biochemistry 2005, 44, (3), 905-914

14. Thorn, K. S.; Naber, N.; Matuska, M.; Vale, R. D.; Cooke, R., Protein Sci. 2000, 9, (2), 213-217

15. Mayer, M. U.; Shi, L.; Squier, T. C., Mol. Biosystems 2005, 1, (1), 53-56. 
16. Giepmans, B. N. G.; Adams, S. R.; Ellisman, M. H.; Tsien, R. Y., Science 2006, 312, (5771), 217-224.

17. Andresen, M.; Schmitz-Salue, R.; Jakobs, S., Mol. Biol. Cell 2004, 15, (12), 5616-5622.

18. Spagnuolo, C. C.; Vermeij, R. J.; Jares-Erijman, E. A., J. Am. Chem. Soc. 2006, 128, (37), 12040-12041.

19. Cao, H.; Chen, B.; Squier, T. C.; Mayer, M. U., Chem. Comm. 2006 $2601-2603$.

20. Mujumdar, R. B.; Ernst, L. A.; Mujumdar, S. R.; Lewis, C. J.; Waggoner, A. S., Bioconjug. Chem. 1993, 4, (2), 105-111.

21. Mujumdar, R. B.; Ernst, L. A.; Mujumdar, S. R.; Waggoner, A. S., Cytometry 1989, 10, (1), 11-19.

22. Li, Q.; Tan, J.; Peng, B. X., Molecules 1997, 2, (6), 91-98.

23. Takeuchi, M.; Mizuno, T.; Shinmori, H.; Nakashima, M.; Shinkai, S., Tetrahedron 1996, 52, (4), 1195-1204.
24. Marqusee, S.; Robbins, V. H.; Baldwin, R. L., Proc. Natl. Acad. Sci. U.S.A. 1989, 86, (14), 5286-5290.

25. Marqusee, S.; Baldwin, R. L., Proc. Natl. Acad. Sci. U.S.A. 1987, 84, (24), 8898-8902.

26. Martin, B. R.; Giepmans, B. N. G.; Adams, S. R.; Tsien, R. Y., Nat Biotechnol. 2005, 23, (10), 1308-1314.

27. Chen, B.; Cao, H.; Yan, P.; Mayer, M. U.; Squier, T. C., Bioconjug. Chem. 2007, in press.

28. Meador, W. E.; Means, A. R.; Quiocho, F. A., Science 1992, 257, (5074), 1251-5.

29. Leevy, W. M.; Gammon, S. T.; Jiang, H.; Johnson, J. R.; Maxwell, D. J.; Jackson, E. N.; Marquez, M.; Piwnica-Worms, D.; Smith, B. D., J. Am. Chem. Soc. 2006, 128, (51), 16476-16477. 